\title{
Effect evaluation of a peer-delivered school-based intervention promoting healthy dietary and physical activity behaviours among secondary vocational students
}

\author{
Gitte Kloek *, Annabelle Kuipers, Thamar Gerritse and Sanne de Vries
}

Research group Healthy Lifestyle in a Supporting Environment, Faculty of Health, Nutrition \& Sport, The
Hague University of Applied Sciences, Johanna Westerdijkplein 75, 2521 EN The Hague, The Netherlands.
annabellekuipers@hotmail.com (A.K.); tigerritse@hotmail.com (T.G.); s.i.devries@hhs.nl (S.I.d.V.).
* Correspondence: g.c.kloek@hhs.nl (G.K.);

\begin{abstract}
This study examines the effectiveness of the peer-delivered, school-based intervention Healthy by Design $(\mathrm{HbD})$. Data were collected in two cross-sectional surveys before and after invention implementation. In total 1,177 vocational students (before: 557, after: 620) participated in an online health behaviour survey. Multilevel logistic and multilevel linear models explored the effect of the intervention over time and the effect of the intervention dose received on (determinants of) dietary of physical activity behaviours. A significant positive effect over time was found for moderate intensity physical activity. A high intervention dose was positively associated with increased water, breakfast and fruit consumption and higher levels of moderate and vigorous physical activity compared to no intervention dose received. A moderate and high intervention dose was negatively associated with high calorie snacks consumption compared to no intervention dose received. Effects of $\mathrm{HbD}$ on the investigated dietary and physical activity behaviours over time are limited, but these effects may be hard to demonstrate and link to the intervention due to the nature of the intervention design and the natural school-setting of this quasi-experimental study. However, a higher intervention dose showed a strong relation with healthier dietary and physical activity behaviours.
\end{abstract}

Keywords: vocational students; healthy lifestyle intervention; physical activity; healthy diet

\section{Introduction}

Obesity is a major problem in today's Western societies and has enormous medical, economic and social consequences [1]. Given that overweight is often due to an energy-imbalance, lifestyle choices are part of this problem [2]. Besides its role in overweight, unhealthy lifestyle choices themselves, like insufficient physical activity and an unhealthy diet, can increase the risk of non-communicable diseases [3-6]. Obesity in adolescence is a strong predictor of obesity in adulthood [7,8]. Therefore, it is important that young people make healthy lifestyle choices [9]. Unfortunately, there is a large group of young people that do not meet the physical activity and dietary guidelines [10]. Furthermore, unhealthy lifestyle choices are not evenly distributed across this group [10-12]. Special attention should go to secondary vocational students as a considerable number are overweight, show low physical activity levels, high levels of sedentary behaviour and often fail to meet the dietary guidelines $[13,14]$. Most secondary vocational students, can be either grouped as late adolescents (16-19-year-olds) or young adults (20-24-year-olds) [15]. It is an age in which they are in the transition from adolescence to adulthood and in a life phase considered as an important time for establishing and intervening on long-term health behaviour patterns $[15,16]$. 
Even though obesity and unhealthy lifestyle choices are a major problem in secondary vocational students, very few health promoting interventions have been developed to improve their health behaviours. The ones that do exist did not prove to be successful in achieving a sustainable change in dietary and physical activity behaviours, or have not been evaluated [17,18]. However, in children and adolescents, many school-based health promoting interventions show a positive effect on physical activity and healthy eating and some showed a decrease in overweight [19-21]. Besides school-based health promoting interventions, peer-delivered interventions also seem to be a promising health promoting intervention strategy. While the effect of these peer-delivered interventions is not always clear and requires more research, many of them show promising results for health behaviours like physical activity and healthy nutrition in adolescents [22-24]. Furthermore, the combination of peer-delivered and school-based strategies in one intervention could be valuable in health promotion for adolescents [25]. A Spanish school-based, peer-led, social marketing intervention for high school students in disadvantaged neighbourhoods for example proved to be effective in increasing fruit consumption and physical activity [26]. In addition to the intervention strategy, theoretical underpinning is suggested to be important to increase effectiveness of lifestyle interventions [27].

Recently, a lifestyle intervention has been developed for vocational students with these limitations in mind. Healthy by Design $(\mathrm{HbD})$ is a school-based, peer-delivered healthy lifestyle intervention promoting dietary and physical activity behaviours in vocational students. In the intervention implementation phase, senior secondary vocational students function as role-models to motivate fellow-students to eat healthy and be physically active. On a weekly basis, they organize health promoting activities, give personal advice and individual support to fellow students who wish to improve their lifestyle. They also distribute the (social) media campaign.

This study aims to investigate the effectiveness of the $\mathrm{HbD}$ intervention on the dietary and physical activity behaviours of vocational students, using a quasi-experimental design. In addition, the second aim is to investigate the influence of the received intervention dose on dietary and physical activity behaviours of vocational students. Behaviour change is however challenging to measure, because lifestyle behaviours like physical activity and diet are complex collections of interacting actions [28]. Therefore, determinants of dietary and physical activity behaviour are also included in this study.

This makes it important to address the underlying theoretical basis of the intervention, which is based on the Environmental Research framework for weight Gain prevention (EnRG) [29]. The EnRG framework states that energy balance-related behaviour is influenced by environment, cognitive mediators and moderators. Both the Theory of Planned Behaviour and the Self-Determination Theory were chosen as underlying theories within this framework following previous results of preliminary research in the intervention design phase [30]. The Theory of Planned Behaviour states that behaviour is underpinned by someone's intention to perform that behaviour. [31]. This intention is influenced by the subjective norm and perceived behavioural control [32]. Social norms have been suggested to be important in the health behaviour of adolescents and young adults, underlining the importance of peers and parental relations [33,34]. In addition to this, motivation seems to be an important determinant in the behaviour of vocational students [35]. Motivation can be seen as a moderator in the EnRG framework. The Self Determination Theory (SDT) is used in various health contexts to explain the construct of motivation by dividing it into autonomous, controlled and amotivation [36-38]. In addition, SDT motivation types have been suggested to influence health behaviour of adolescents and have been named as promising intervention targets [39,40]. In addition to underlying theories, it is important to acknowledge the complexity of this effect evaluation due to the school-based nature of the $\mathrm{HbD}$ intervention and its multiple interacting components and various outcome measures and variables [41-43].

\section{Materials and Methods}




\subsection{Intervention programme}

The $\mathrm{HbD}$ intervention is a school-based healthy lifestyle intervention for secondary vocational students aged sixteen years and older. In the Netherlands, students following secondary vocational education are mostly between 16 and 24 years old and attend one of the four levels of a vocational education and training (VET) programme [44]. The main aim of the $\mathrm{HbD}$ intervention was to promote a sustainable change in the (determinants of) dietary and physical activity behaviours among vocational students. More specifically:

- Increase the daily consumption of water

- Reduce the daily consumption of soft and energy drinks

- Reduce the daily intake of unhealthy snacks

- Promote daily breakfast consumption

- Increase the daily intake of fruits

- Increase daily walking

- Increase weekly sport activities

- Improve knowledge on dietary and physical activity guidelines

- Improve social support on healthy dietary and physical activity behaviours

- Improve motivation for healthy dietary and physical activity behaviours

The intervention program was conducted for and by vocational students under supervision of a $\mathrm{HbD}$ coordinator and consisted of two parts: an internship program and a (social) media campaign. The intervention activities were conducted by interns, senior Lifestyle \& Sports students who acted as so called 'Fit Coaches' to motivate their fellow students for a healthy lifestyle. Table 1 gives an overview of all intervention components, their function and the behaviour change techniques that were incorporated [45].

Table 1. Healthy by Design intervention components, intervention function and behaviour change techniques targeted.

\begin{tabular}{|c|c|c|}
\hline Intervention components & Function & Behaviour change techniques \\
\hline \multirow{4}{*}{$\begin{array}{l}\text { Physical activity classes orga- } \\
\text { nized per vocational education } \\
\text { training programme }\end{array}$} & Training & Social support \\
\hline & Modelling & $\begin{array}{c}\text { Instruction how to perform the } \\
\text { behaviour }\end{array}$ \\
\hline & & $\begin{array}{c}\text { Demonstration of the behav- } \\
\text { iour }\end{array}$ \\
\hline & & Behavioural practice \\
\hline \multirow[t]{2}{*}{$\begin{array}{l}\text { Healthy lifestyle events per } \\
\text { school location }\end{array}$} & $\begin{array}{l}\text { Attention* } \\
\text { Persuasion }\end{array}$ & $\begin{array}{l}\text { Information about health con- } \\
\text { sequences }\end{array}$ \\
\hline & & $\begin{array}{l}\text { Material incentive } \\
\text { Behavioural practice }\end{array}$ \\
\hline In class nutrition education & $\begin{array}{l}\text { Education } \\
\text { Persuasion }\end{array}$ & $\begin{array}{l}\text { Information about health con- } \\
\text { sequences }\end{array}$ \\
\hline \multirow[t]{3}{*}{ Cooking classes } & $\begin{array}{l}\text { Persuasion } \\
\text { Training }\end{array}$ & $\begin{array}{l}\text { Salience of consequences } \\
\text { Instruction how to perform the } \\
\text { behaviour }\end{array}$ \\
\hline & & $\begin{array}{c}\text { Demonstration of the behav- } \\
\text { iour }\end{array}$ \\
\hline & & Behavioural practice \\
\hline \multirow{3}{*}{$\begin{array}{l}\text { Personal coaching of fellow } \\
\text { students on healthy lifestyle } \\
\text { goals }\end{array}$} & Persuasion & Goal setting \\
\hline & Training & Action planning \\
\hline & & $\begin{array}{l}\text { Feedback on behaviour } \\
\text { Social support }\end{array}$ \\
\hline In school media campaign & $\begin{array}{l}\text { Attention } \\
\text { Education }\end{array}$ & $\begin{array}{l}\text { Information about health con- } \\
\text { sequences }\end{array}$ \\
\hline
\end{tabular}


Social media campaign
Attention

Education

Persuasion
Salience of consequences

Prompts/cues

Information about health con-

sequences

Salience of consequences

Prompts/cues

* attention is not an intervention function according to Michie et al. [45] but these components also served the purpose of drawing overall attention to $\mathrm{HbD}$ intervention activities

\subsection{Study design and intervention implementation}

The HbD intervention was implemented in school years 2017-2018 and 2018-2019 at two locations of a secondary vocational school in an urban area of the Netherlands. A quasi-experimental design was used with two experimental locations and one control location. This is depicted in figure 1 . The two experimental locations will be referred to as location A and B. One control location, location C, did not implement the intervention. Implementation took place in phases; location A participated for one year, whereas location B participated for two years in the intervention. All students of the experimental locations were exposed to multiple components of the intervention. They were however free to choose whether they participated in the planned activities.

To carry out the effect evaluation, the intention of this study was to measure all participants' (determinants of) dietary and physical activity behaviour longitudinally and compare control with experimental groups. Control location $C$ however eventually refused participation after the baseline measurement, causing the control group to be excluded from the study. In addition, longitudinal measurements among the experimental group were not possible due to the very low response rate of $13 \%$ at follow-up. This problem persisted regardless of various incentives offered to participants of the baseline measurement, like the possibility of winning a gift voucher. Therefore, the study design had to be changed into a repeated cross-sectional design without a control group. The baseline measurement was performed at the beginning of the first school year in November 2017-January 2018. The follow-up measurement was performed at the end of the second school year in May-June 2019.

\subsection{Study population}

Participants were recruited by convenience sampling. Secondary vocational schools were contacted and then made a selection of classes that were visited by the researchers. Participation in the study was on a voluntary basis. For the baseline measurement, only first and second year vocational students were included. For the follow-up measurement, all first, second, third and fourth year secondary vocational students were included. Participants under sixteen years of age were excluded for both measurements. Every participant received information about the study beforehand via email and filled in an electronic consent form during class before taking the digital survey. As can be seen in the flow chart of Figure 1, a total of 1,177 students were included in the study sample, 557 at baseline and 620 at follow-up. This study was exempted from review by the Medical Ethics Committee Southwest Holland, because it is not within the scope of the Dutch Medical Research Involving Human Subjects Act [46]. 


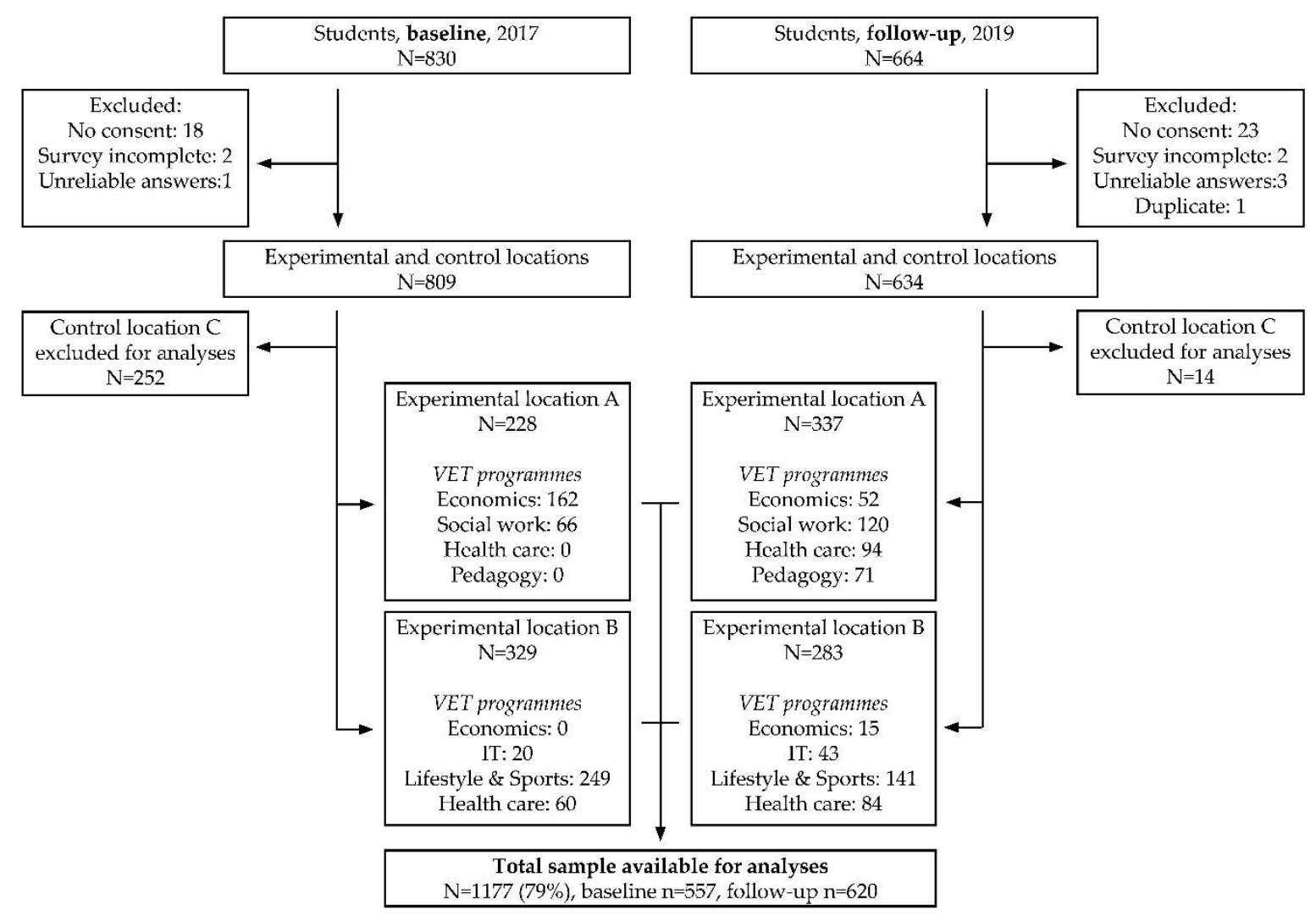

Figure 1. Flow chart of the study sample. VET = vocational education and training

\subsection{Data collection}

\subsubsection{Dietary behaviours}

Personal characteristics and dietary behaviour were measured using questions of the periodic youth health monitor system of the Dutch regional health authorities [47]. Participants were asked how many days per week they consumed breakfast, fruit, water, soda, and sweet and savoury snacks. Furthermore, they were asked about the quantity they usually consumed of these dietary variables on those days.

\subsubsection{Physical activity behaviours}

The Short QUestionnaire to ASsess Health- enhancing physical activity (SQUASH) was included to measure the total time spent in in light, moderate and vigorous physical activity by asking participants about the number of days per week they spend walking, biking and doing sports amongst others, in addition to the duration of this physical activity. Even though this questionnaire has been proven valid, some questions had to be adapted beforehand by the researchers to ensure clarity for the target group [48]. An example of this is that work related physical activity was changed into side job related physical activity.

\subsubsection{Determinants of dietary and physical activity behaviours}

The type of motivation (i.e. autonomous motivation, controlled motivation and amotivation) was measured separately for dietary and physical activity behaviour, using the Treatment Self-Regulation Questionnaire (TSRQ). This questionnaire asks participants to score various statements related to the three types of motivation, using a five point scale [49].

Besides the various types of motivation, the perceived descriptive norm was also measured. This subtype of the social norm is defined as what we believe that (our important) others would do concerning a specific behaviour [31]. This perceived descriptive 
norm was measured by asking the students how often they think their friends perform certain health behaviour. One of the questions was for example: 'how often do your friends drink soda?'. Answer options included a five point scale, ranging from never to very often. Students that answered with 'I don't know', were excluded from further analysis on this topic.

Knowledge of the guidelines for fruit consumption and physical activity was measured by asking the students if they know what the Dutch guidelines for fruit consumption and physical activity are [50,51]. The guideline for physical activity for adults differs from the guideline for youth under eighteen [51]. Therefore, the knowledge of both guidelines was measured. This was done by giving the participants multiple answer options from which they had to select the correct option.

\subsubsection{Background variables}

Covariates included age, gender, Body mass index, level of education and type of vocational school. BMI was determined using the self-reported body weight and height of the participant. Level of vocational education included level 2, 3 and 4. Participants attended six different types of VET programmes, as can be seen in the flow chart of Figure 1.

\subsection{Data analysis}

Due to the cross-sectional nature of the study, the follow-up measurement included different students compared to the baseline measurement. To investigate the effectiveness of the $\mathrm{HbD}$ intervention, several outcome measures were investigated. These include the above mentioned dietary and physical activity behaviours and their determinants. For dietary behaviours, the results of the survey questions were used to calculate the average daily or weekly intake of each dietary variable. The Netherlands Nutrition Centre advises to consume a maximum of three unhealthy products per week, the so-called week choices [50]. Therefore, a sum score was made to indicate the number of high calorie snacks. This included the number of sweet and savoury snacks and the number of portions of $250 \mathrm{~mL}$ of energy drink and soda. For physical activity, the average number of minutes per week that participants engaged in moderate and vigorous physical activity was calculated.

SDT motivation types were calculated by averaging the scores of the different types of statements, which resulted in the average autonomous, controlled and amotivation score for both diet and physical activity behaviour. Following the method of Ball et al. [52], the measured answers to perceived descriptive norm questions for dietary and physical activity behaviours were dichotomized into the options almost never/not very often/neutral and (very) often. This resulted in dichotomous perceived descriptive norm variables for water, soda, fruit, sports and walking. Knowledge of the fruit and physical activity guidelines was dichotomised in yes, when participants selected the right guideline as their answer, and no when they failed to give the right answer.

Two different models were used to investigate the effect of the intervention on the outcome measures. In the first model, the effect over time on the outcome variables was investigated. This was done by including time of measurement (baseline or follow-up) in the model, which revealed whether there were significant changes in the (determinants of) behaviour of participants over time. However, Healthy by Design is a complex intervention in a real-life school-setting. Changes in behaviour over time can be influenced by many factors other than the intervention and it is likely that exposure to the intervention varied in the study sample. Therefore the second model, investigated the effect of intervention dose received on the outcome measures. As suggested by Pirie et al.[53], dose received was calculated using various survey questions asking about exposure to the intervention, like 'Have you seen $\mathrm{HbD}$ on social media?' or 'Did you participate in any of these intervention activities: ... .'. The answers were added up and this sum score was then categorized into 'no dose', 'low dose' and 'high dose' received, based on equal distribution of these three groups at follow-up. At baseline, all participants were attributed to the 'no dose' received group. 
Statistical analyses were performed using SPSS 25. Variance analysis was performed and outliers were removed from analysis where necessary. Data had a multilevel structure; participants were nested within the type of VET programme they attended. To take this nesting into account, multilevel modelling was performed with VET programme as the random effect. In addition, the model was corrected for age, BMI, gender, location and level of VET education. These covariates were chosen based on literature and the expected interaction with both the outcome measures and tested variables [54-56]. Multilevel logistic and multilevel linear regression were used to estimate either ORs or betas explaining the effects over time and the effect of intervention dose received on the mentioned outcome measures. Statistical significance was tested using an alpha of 0.05. To investigate the variation due to the nested structure of the data, the Intraclass Correlation Coefficient (ICC) was calculated.

\section{Results}

\subsection{Sample characteristics}

Table 2 presents the study sample characteristics, measured at baseline and follow-up. A total of 557 students participated at baseline with a mean age of 17.6 years. At follow-up, a total of 620 students participated with a mean age of 19.8 years. The gender, age and BMI of the follow-up group differed significantly from the baseline group. The received intervention dose was distributed as follows at follow-up; $36 \%$ of participants were not exposed to the intervention at all, 30\% received a low intervention dose and $34 \%$ received a high dose. The calculated frequencies and descriptive measures for (the determinants of) the investigated dietary and physical activity behaviours can be found in Appendix A.

Table 2. Study population characteristics at baseline and follow-up.

\begin{tabular}{|c|c|c|c|c|c|c|}
\hline & \multicolumn{3}{|c|}{ Baseline } & \multicolumn{3}{|c|}{ Follow-up } \\
\hline & Location A & Location B & Total & Location A & Location B & Total \\
\hline $\mathbf{N}$ & 228 & 329 & 557 & 337 & 283 & 620 \\
\hline \multicolumn{7}{|l|}{ Gender } \\
\hline Male & $30 \%$ & $62 \%$ & $49 \%$ & $16 \%$ & $57 \%$ & $35 \% * *$ \\
\hline Female & $70 \%$ & $38 \%$ & $51 \%$ & $84 \%$ & $43 \%$ & $65 \%$ \\
\hline Age (years) & 17.7 & 17.4 & 17.6 & 20.5 & 19.0 & $19.8^{* *}$ \\
\hline $\begin{array}{l}\text { Standard devia- } \\
\text { tion }\end{array}$ & 1.7 & 1.6 & 1.7 & 5.7 & 2.1 & 4.5 \\
\hline BMI $\left(\mathrm{kg} / \mathrm{m}^{2}\right)$ & 22.5 & 21.8 & 22.0 & 23.5 & 22.9 & $23.2^{* *}$ \\
\hline $\begin{array}{l}\text { Standard devia- } \\
\text { tion }\end{array}$ & 3.3 & 2.7 & 2.9 & 4.5 & 3.9 & 4.3 \\
\hline \multicolumn{7}{|l|}{ VET level } \\
\hline Level 2 & $0 \%$ & $10 \%$ & $6 \%$ & $0 \%$ & $12 \%$ & $5 \%$ \\
\hline Level 3 & $3 \%$ & $32 \%$ & $20 \%$ & $19 \%$ & $24 \%$ & $21 \%$ \\
\hline Level 4 & $97 \%$ & $58 \%$ & $74 \%$ & $81 \%$ & $64 \%$ & $74 \%$ \\
\hline
\end{tabular}

\subsection{Dietary and physical activity behaviours}

The results of the multilevel linear regression analyses for dietary behaviour can be found in table 3 . In the first model - testing differences in outcome variables over time there are no significant effects between the baseline and follow-up measurement for any of the dietary variables. In the second model - testing the effect of the intervention dose received - a low intervention dose shows a significant negative association with high calorie snacks in reference to no intervention dose. Receiving a high intervention dose was significantly associated with less high calorie snacks and more breakfast, water and fruit consumption compared to not being exposed to the intervention. 
Table 3. Multilevel estimates for the associations between dietary behaviour and intervention factors

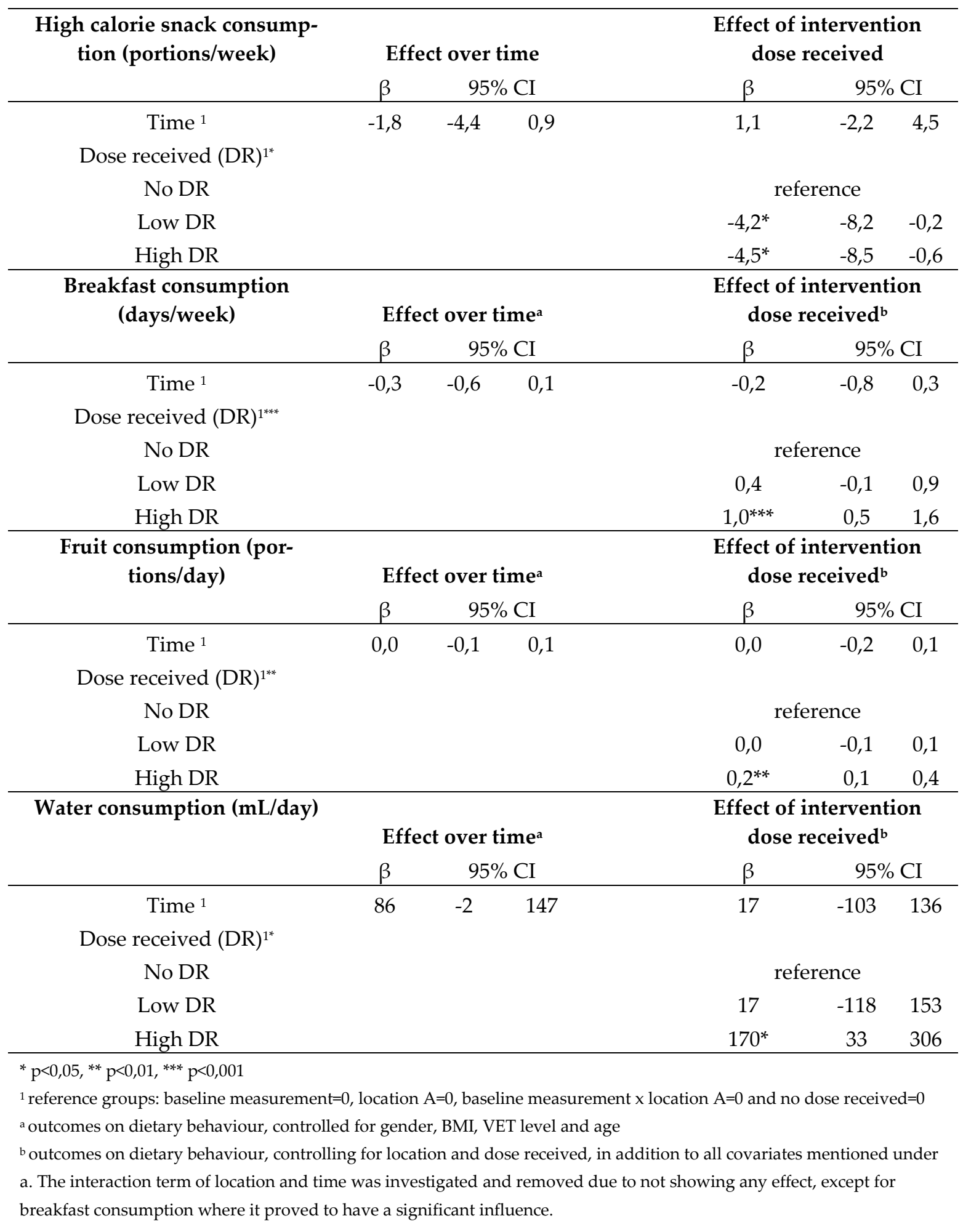

Table 4 shows the associations between the intervention factors and physical activity behaviour. There is a significant positive effect over time for moderate intensity physical activity. In the dose received model, a high intervention dose received shows a significant positive association with the amount of moderate intensity physical activity per week compared to no intervention dose. This is the same for vigorous intensity physical activity and moderate and vigorous intensity physical activity combined.

Table 4. Multilevel estimates for the associations between physical activity behaviour and intervention factors 


\begin{tabular}{|c|c|c|c|c|c|c|}
\hline \multirow[t]{2}{*}{$\begin{array}{l}\text { Moderate intensity physical activity } \\
\text { (min/week) }\end{array}$} & \multicolumn{3}{|c|}{ Effect over time ${ }^{a}$} & \multicolumn{3}{|c|}{$\begin{array}{l}\text { Effect of intervention } \\
\text { dose received }\end{array}$} \\
\hline & $\beta$ & \multicolumn{2}{|c|}{$95 \% \mathrm{CI}$} & $\beta$ & \multicolumn{2}{|c|}{$95 \% \mathrm{CI}$} \\
\hline Time $^{1}$ & $97^{*}$ & 11 & 183 & 15 & -100 & 131 \\
\hline \multicolumn{7}{|l|}{ Dose received $(\mathrm{DR})^{1}$} \\
\hline No DR & & & & \multicolumn{3}{|c|}{ reference } \\
\hline Low DR & & & & 67 & -65 & 199 \\
\hline High DR & & & & $150^{*}$ & 17 & 282 \\
\hline \multirow[t]{2}{*}{$\begin{array}{l}\text { Vigorous intensity physical activity } \\
\text { (min/week) }\end{array}$} & \multicolumn{3}{|c|}{ Effect over time $^{a}$} & \multicolumn{3}{|c|}{$\begin{array}{l}\text { Effect of intervention } \\
\text { dose received }\end{array}$} \\
\hline & $\beta$ & \multicolumn{2}{|c|}{$95 \% \mathrm{CI}$} & $\beta$ & \multicolumn{2}{|c|}{$95 \% \mathrm{CI}$} \\
\hline Time $^{1}$ & -25 & -60 & 11 & $-65^{* *}$ & -113 & -16 \\
\hline \multicolumn{7}{|l|}{ Dose received $(\mathrm{DR})^{1^{*}}$} \\
\hline No DR & & & & \multicolumn{3}{|c|}{ reference } \\
\hline Low DR & & & & 39 & -14 & 92 \\
\hline High DR & & & & $67^{*}$ & 15 & 123 \\
\hline \multirow[t]{2}{*}{$\begin{array}{l}\text { Moderate \& vigorous intensity } \\
\text { physical activity (min/week) }\end{array}$} & \multicolumn{3}{|c|}{ Effect over time $^{a}$} & \multicolumn{3}{|c|}{$\begin{array}{l}\text { Effect of intervention } \\
\text { dose received }\end{array}$} \\
\hline & $\beta$ & \multicolumn{2}{|c|}{$95 \% \mathrm{CI}$} & $\beta$ & \multicolumn{2}{|c|}{$95 \% \mathrm{CI}$} \\
\hline Time $^{1}$ & 78 & -18 & 173 & -49 & -176 & 79 \\
\hline \multicolumn{7}{|l|}{ Dose received $(\mathrm{DR})^{1^{*}}$} \\
\hline No DR & & & & \multicolumn{3}{|c|}{ reference } \\
\hline Low DR & & & & 103 & -40 & 245 \\
\hline High DR & & & & $219^{*}$ & 74 & 363 \\
\hline \multicolumn{7}{|l|}{${ }^{*} \mathrm{p}<0,05,{ }^{* *} \mathrm{p}<0,01,{ }^{* * *} \mathrm{p}<0,001$} \\
\hline \multicolumn{7}{|c|}{$\begin{array}{l}{ }^{1} \text { reference groups: baseline measurement, location } 2 / 3 \text {, baseline measurement } x \text { location } 2 / 3 \text { and no dose received } \\
\text { a outcomes on PA behaviour, controlled for gender, BMI, VET level and age }\end{array}$} \\
\hline
\end{tabular}

\subsection{Determinants of dietary and physical activity behaviours}

The regression estimates for the determinants of dietary behaviour are shown in table 5 . In the first model, it can be seen that there was a negative significant effect for the autonomous motivation score over time. In the dose received model, this effect becomes significantly positive. In addition, there was a positive effect for the amotivation score for diet over time. In the dose received model, there is a positive association with a low intervention dose compared to no intervention dose for amotivation.

Table 5. Multilevel estimates for the associations between determinants of dietary behaviour and intervention factors

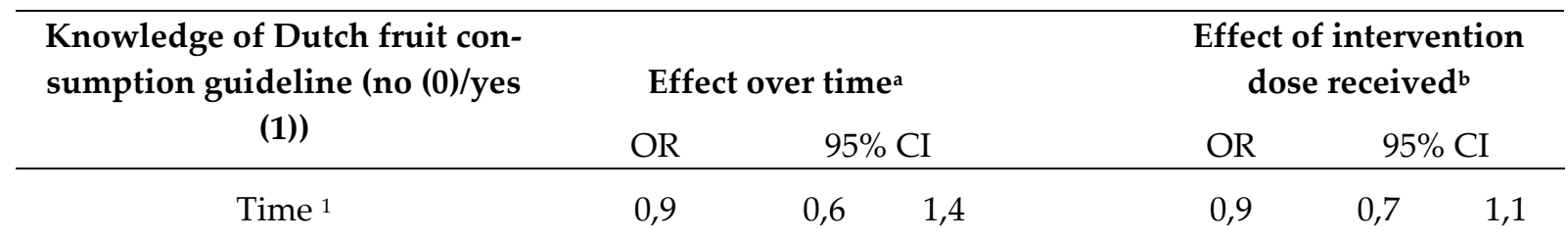

Dose received (DR) $)^{1 * * *}$

No DR

Low DR

High DR reference

$\begin{array}{lll}1,5 & 0,9 & 2,6 \\ 0,6 & 0,4 & 1,0\end{array}$




\begin{tabular}{cc}
\hline $\begin{array}{c}\text { Perceived descriptive norm for } \\
\text { water consumption ((strong- }\end{array}$ Effect over time & $\begin{array}{c}\text { Effect of intervention } \\
\text { dose received }^{\mathrm{b}}\end{array}$
\end{tabular}

ly)disagree \& neutral (0) vs.

(strongly)agree (1))

\begin{tabular}{cccccc} 
OR & \multicolumn{2}{c}{$95 \%$ CI } & OR & \multicolumn{2}{c}{$95 \%$ CI } \\
\hline 1,2 & 0,9 & 1,6 & 1,0 & 0,7 & 1,4
\end{tabular}

Dose received (DR) ${ }^{1}$

No DR

reference

\begin{tabular}{ccccc} 
Low DR & 1,4 & 0,8 & 2,4 \\
High DR & 1,4 & 0,8 & 2,3 \\
\hline $\begin{array}{c}\text { Perceived descriptive norm for } \\
\text { soda consumption ((strong- } \\
\text { ly)disagree \& neutral (0) vs. }\end{array}$ & Effect over time ${ }^{\mathrm{a}}$ & $\begin{array}{c}\text { Effect of intervention } \\
\text { dose received }\end{array}$ \\
(1)
\end{tabular}

\begin{tabular}{|c|c|c|c|c|}
\hline$\left(\right.$ strongly)agree (1)) ${ }^{2}$ & OR & $95 \% \mathrm{CI}$ & OR & $95 \%$ CI \\
\hline Time $^{1}$ & 0,8 & 0,6 & 0,9 & 0,6 \\
\hline
\end{tabular}

Dose received (DR) ${ }^{1}$

No DR

reference

\begin{tabular}{lcccc} 
Low DR & 0,8 & 0,3 & 1,3 \\
High DR & 1 & 0,6 & 1,6 \\
\hline descriptive norm for & Effect over time & Effect of intervention \\
dose received $^{\mathrm{b}}$
\end{tabular}

ly)disagree \& neutral (0) vs.

(strongly)agree (1))

\begin{tabular}{llllll} 
OR & \multicolumn{2}{c}{$95 \%$ CI } & OR & \multicolumn{2}{c}{$95 \%$ CI } \\
1,0 & 0,7 & 1,5 & 1,2 & 0,8 & 1,8
\end{tabular}

Follow-up measurement ${ }^{1}$

Dose received (DR) ${ }^{1}$

No DR

Low DR

reference

High DR

$1 \quad 0,6 \quad 1,7$

0,8

$0,4 \quad 1,3$

Autonomous motivation score

for dietary behaviour

Effect over time ${ }^{a}$

Effect of intervention

dose received ${ }^{\mathrm{b}}$

\begin{tabular}{ccccccc} 
& \multicolumn{2}{c}{$95 \%$ CI } & \multicolumn{2}{c}{$\beta$} & \multicolumn{2}{c}{$95 \%$ CI } \\
\hline Time $^{1}$ & $-0,1^{* *}$ & $-0,3$ & 0,0 & $0,2^{*}$ & $-0,3$ & 0,0
\end{tabular}

Dose received (DR) ${ }^{1}$

No DR

Low DR

High DR

Controlled motivation score for dietary behaviour

(1)

reference

$-0,1 \quad-0,2 \quad 0,1$

$0,1 \quad-0,1 \quad 0,3$

Effect of intervention

Effect over time $^{\mathrm{a}} \quad$ dose received ${ }^{\mathrm{b}}$

$\begin{array}{lllllll}\text { Time }^{1} & 0,0 & -0,1 & 0,1 & 0,0 & -0,2 & 0,1\end{array}$

Dose received (DR) ${ }^{1}$

No DR

reference

Low DR

$0,0 \quad-0,1 \quad 0,2$ 


\begin{tabular}{|c|c|c|c|c|c|c|}
\hline High DR & & & & 0,1 & $-0,1$ & 0,2 \\
\hline \multirow[t]{2}{*}{$\begin{array}{c}\text { Amotivation score for dietary } \\
\text { behaviour }\end{array}$} & \multicolumn{3}{|c|}{ Effect over time } & \multicolumn{3}{|c|}{$\begin{array}{l}\text { Effect of intervention } \\
\text { dose received }^{b}\end{array}$} \\
\hline & $\beta$ & \multicolumn{2}{|c|}{$95 \%$ CI } & $\beta$ & \multicolumn{2}{|c|}{$95 \% \mathrm{CI}$} \\
\hline Time ${ }^{1}$ & $0,1^{*}$ & 0,0 & 0,2 & 0,1 & $-0,1$ & 0,2 \\
\hline \multicolumn{7}{|l|}{ Dose received $(\mathrm{DR})^{1^{*}}$} \\
\hline No DR & & & & \multicolumn{3}{|c|}{ reference } \\
\hline Low DR & & & & $0,2^{*}$ & 0,0 & 0,3 \\
\hline High DR & & & & 0,0 & $-0,2$ & 0,1 \\
\hline \multicolumn{7}{|l|}{${ }^{*} \mathrm{p}<0,05,{ }^{* *} \mathrm{p}<0,01,{ }^{* * *} \mathrm{p}<0,001$} \\
\hline \multirow{2}{*}{\multicolumn{7}{|c|}{$\begin{array}{l}{ }^{1} \text { reference groups: baseline measurement }=0 \text {, location } A=0 \text {, baseline measurement } x \text { location } A=0 \text { and no dose received }=0 \\
{ }^{2} \text { the program was unable to fit this multilevel model, therefore a normal logistic regression was performed, correcting for } \\
\text { school as confounder }\end{array}$}} \\
\hline & & & & & & \\
\hline \multicolumn{7}{|c|}{ a outcomes on dietary behaviour, controlled for gender, BMI, VET level and age } \\
\hline \multicolumn{7}{|c|}{$\begin{array}{l}\text { b outcomes on dietary behaviour, controlling for location, in addition to all covariates mentioned under a. The interaction term } \\
\text { of location and time was investigated and removed because it was not significant }\end{array}$} \\
\hline
\end{tabular}

In table 6, the regression estimated for the determinants of physical activity behaviour are shown. There was a decrease in the odds of knowing the physical activity guidelines for adults over time. For the knowledge of the physical activity guideline under 18, there was however an increase in odds over time. There was also a decrease in autonomous motivation for physical activity over time according to the effect over time model, this however turned into a slight increase in the dose received model. A low intervention dose received showed an increase in controlled motivation for physical activity compared to no dose received. A high dose received decreased the amotivation score for physical activity compared to no dose received.

Table 6. Multilevel estimates for the associations between determinants of physical activity behaviour and intervention factors

\begin{tabular}{|c|c|c|c|c|c|}
\hline \multirow{3}{*}{$\begin{array}{l}\begin{array}{l}\text { Knowledge of Dutch physical activity } \\
\text { guideline }>\mathbf{1 8}(\text { no }(0) / \text { yes (1)) }\end{array} \\
\text { Time }^{1}\end{array}$} & \multicolumn{2}{|c|}{ Effect over time } & \multicolumn{3}{|c|}{$\begin{array}{l}\text { Effect of interven- } \\
\text { tion dose received }\end{array}$} \\
\hline & OR & $95 \% \mathrm{CI}$ & OR & \multicolumn{2}{|c|}{$95 \% \mathrm{CI}$} \\
\hline & $0,2^{* * *}$ & 0,2 & $0,2^{* *}$ & 0,1 & 0,5 \\
\hline \multicolumn{6}{|l|}{ Dose received $(\mathrm{DR})^{1}$} \\
\hline No DR & & & \multicolumn{3}{|c|}{ reference } \\
\hline Low DR & & & 1,4 & 0,7 & 3,0 \\
\hline High DR & & & 1,1 & 0,6 & 2,0 \\
\hline \multirow[t]{2}{*}{$\begin{array}{l}\text { Knowledge of Dutch physical activity } \\
\text { guideline }<18 \text { (no (0)/yes (1)) }\end{array}$} & \multicolumn{2}{|c|}{ Effect over time $^{a}$} & \multicolumn{3}{|c|}{$\begin{array}{l}\text { Effect of interven- } \\
\text { tion dose received }{ }^{b}\end{array}$} \\
\hline & OR & $95 \% \mathrm{CI}$ & OR & \multicolumn{2}{|c|}{$95 \%$ CI } \\
\hline Time $^{1}$ & $1,6^{*}$ & 1,0 & 1,3 & 0,7 & 2,6 \\
\hline \multicolumn{6}{|l|}{ Dose received $(\mathrm{DR})^{1}$} \\
\hline No DR & & & \multicolumn{3}{|c|}{ reference } \\
\hline Low DR & & & 1,3 & 0,6 & 2,5 \\
\hline High DR & & & 1,3 & 0,6 & 2,5 \\
\hline \multirow{2}{*}{$\begin{array}{l}\text { Perceived descriptive norm for sports } \\
\text { ((strongly)disagree \& neutral (0) vs. } \\
\text { (strongly)agree (1)) }\end{array}$} & Effect & er time ${ }^{a}$ & \multicolumn{3}{|c|}{$\begin{array}{l}\text { Effect of interven- } \\
\text { tion dose received }\end{array}$} \\
\hline & OR & $95 \% \mathrm{CI}$ & OR & & $\mathrm{CI}$ \\
\hline Time ${ }^{1}$ & 0,8 & $0,7 \quad 1,0$ & 0,8 & 0,5 & 1,2 \\
\hline
\end{tabular}


Dose received $(\mathrm{DR})^{1}$

\begin{tabular}{|c|c|c|c|c|c|}
\hline No DR & & & \multicolumn{3}{|c|}{ reference } \\
\hline Low DR & & & 1,1 & 0,6 & 1,9 \\
\hline High DR & & & 1,0 & 0,6 & 1,7 \\
\hline $\begin{array}{l}\text { scriptive norm for walk- } \\
\text { y)disagree \& neutral (0) }\end{array}$ & Effe & er time ${ }^{a}$ & \multicolumn{3}{|c|}{$\begin{array}{l}\text { Effect of interven- } \\
\text { tion dose received }\end{array}$} \\
\hline trongly)agree (1)) & OR & $95 \%$ CI & OR & \multicolumn{2}{|c|}{$95 \% \mathrm{CI}$} \\
\hline Time ${ }^{1}$ & 0,8 & $0,6 \quad 1,1$ & 1,0 & 0,6 & 1,6 \\
\hline
\end{tabular}

Dose received $(\mathrm{DR})^{1}$

No DR reference

Low DR $0,8 \quad 0,5 \quad 1,3$

High DR

$0,7 \quad 0,4 \quad 1,3$

Autonomous motivation score for physical activity

Effect of interven-

$\begin{array}{ccccccc} & \beta & 95 \% \text { CI } & \beta & 95 \% \text { CI } \\ \text { Time }^{1} & -0,1^{*} & -0,2 & 0,0 & 0,2^{*} & -0,3 & 0,0\end{array}$

Dose received $(\mathrm{DR})^{1}$

No DR

reference

Low DR

$0,0 \quad-0,2 \quad 0,2$

High DR

$0,2 \quad 0,0 \quad 0,3$

Controlled motivation score for physical activity

Effect of interven-

\begin{tabular}{ccccccc} 
physical activity & \multicolumn{2}{c}{ Effect over time $^{\mathbf{a}}$} & \multicolumn{3}{c}{ tion dose received } \\
& $\beta$ & $95 \%$ CI & $\beta$ & $95 \%$ CI \\
\hline Time $^{1}$ & 0,0 & $-0,1$ & 0,1 & 0,0 & $-0,1$ & 0,2
\end{tabular}

Dose received $(\mathrm{DR})^{1}$

No DR

Low DR

High DR

Amotivation score for physical activity

Time ${ }^{1}$

1

Dose received $(\mathrm{DR})^{1^{* *}}$

No DR

Low DR

High DR reference

Effect of intervention dose received ${ }^{b}$

\begin{tabular}{cccccc}
\multicolumn{2}{c}{$\begin{array}{c}\text { Effect over time } \\
\beta\end{array}$} & $95 \%$ & CI & \multicolumn{2}{c}{$\begin{array}{c}\text { tion dose received } \\
\text { tion }\end{array}$} \\
0,1 & 0,0 & 0,2 & $\beta$ & $95 \%$ & CI \\
\hline
\end{tabular}

reference

$0,1 \quad-0,1 \quad 0,2$

$-0,2^{*} \quad-0,4 \quad 0,0$

${ }^{*} \mathrm{p}<0,05,{ }^{* *} \mathrm{p}<0,01,{ }^{* * *} \mathrm{p}<0,001$

${ }^{1}$ reference groups: baseline measurement, location $2 / 3$, baseline measurement $x$ location $2 / 3$ and no dose received ${ }^{a}$ outcomes on dietary behaviour, controlled for gender, BMI, VET level and age

${ }^{b}$ outcomes on dietary behaviour, controlling for location, in addition to all covariates mentioned under a. The interaction

term of location and time was investigated and removed because it was not significant

\section{Discussion}

The first objective of this study was to investigate the effectiveness of the Healthy by Design intervention on the (determinants of) dietary and physical activity behaviour of VET students. Secondly, the study aimed to investigate the effect of the intervention dose received on these outcome measures. 
Some effects on the (determinants of) dietary and physical activity behaviour over time were found. Moderate intensity physical activity showed an increase over time. There was also an increase in the odds of knowing the Dutch physical activity guideline for people under 18 years old over time. These positive effects could have been influenced by the intervention. A direct link to the intervention can however not be made, due to the various influences over time in a natural setting. There was also a significant decrease in the odds of knowing the Dutch physical activity guidelines for adults over time. It is unlikely that this is linked to the intervention, because there had been a change in the physical activity guidelines in The Netherlands between baseline and follow-up. Participants thus might have had knowledge of the old guideline instead of the new one, as it takes time for new information to become common knowledge. In addition, there was a negative effect over time for the autonomous motivation score for both dietary and physical activity behaviour and a positive one for the amotivation score for dietary behaviour. This can also not be directly linked to the effect of the intervention due to the natural setting of the study.

Looking at the second objective of the study, results showed that the intervention dose that participants received plays a role in many of the investigated health behaviours. Both a low and high intervention dose received showed a significant decrease in the consumption of high calorie snacks compared to no dose received. In addition, a high dose received was positively associated with increased breakfast, fruit and water consumption, as well as more time spend in moderate, vigorous and moderate and vigorous physical activity. This shows that a high exposure to the intervention is associated with healthier dietary and physical activity behaviour. In contrast, the received intervention dose seems to have less influence on the determinants of health behaviour. A high intervention dose did show a decrease in amotivation for physical activity compared to no intervention dose. However, a low intervention dose was positively associated with amotivation for dietary behaviour compared to receiving no intervention dose. A possible explanation for this is that participants in this group might have been in contact with the intervention but then decided not to participate due to a lack of motivation. Participants in the no dose group however never came into contact with the intervention at all. A low intervention dose also showed an association with an increase in controlled motivation for physical activity. This finding would generally not be seen as positive, because controlled motivation does not lead to sustainable behaviour change [57]. However, Philips et al. [57] hypothesize that an increase in controlled motivation is not necessarily detrimental, because the influence of controlled motivation depends on its relative position to the other types of motivation and could thus still be beneficial for healthy behaviour.

Over time, there are positive effects on moderate physical activity and on knowledge of the physical activity guideline under 18 years old. This is in line with effect evaluations of school-based healthy eating and physical activity interventions for other target groups, as they often show moderate evidence of their effect [19]. A school-based intervention with a similar target group of students between 15 and 24 years old found a reduction in physical inactivity, which is in line with the present study [58]. Because of the methodological difficulties in this study, the real effects of the $\mathrm{HbD}$ intervention on the (determinants of) dietary and physical activity of vocational students over time are hard to determine due to the natural setting of the study. Literature states that both the peer-delivered and school-based component of $\mathrm{HbD}$ are promising for improving both dietary and physical activity behaviour[19-24]. Combining these components however also makes the intervention a very complex one, which could have contributed to the minimal effects that were found over time[41]. Trude et al. [59] state that in complex interventions with a high likelihood of participant contamination, like in this study, an analysis using dose received information can provide important dose-response estimates. Therefore, including the intervention dose received model provides valuable secondary evaluation analysis. This suggests that low exposure to an intervention is not enough to promote behaviour change. It is thus important to make sure than students come into 
contact with intervention components on a regular basis. In addition, intervention dose seems to be related to amotivation, leading to an increase in amotivation for diet when the intervention dose is low, and a decrease in amotivation for physical activity when the intervention dose is high. This further underlines the fact that motivation is an important determinant to consider in health promoting interventions, as is also shown in previous studies[39].

This study has several limitations. The use of self-administered questionnaires to measure (determinants) of dietary and physical activity behaviour is a limitation in this study, due to a risk of recall bias and the use of socially desirable answers [60]. In addition, the SQUASH questionnaire is known to cause a slight overestimation of the physical activity level of participants [61]. The exact effect of these questionnaire limitations on the results can however not be inferred. Another limitation of this study is the use of cross-sectional data. Due to the fact that there could be no longitudinal data collection, the causal effect of the intervention could not be determined. Since the control location dropped out of the study, no comparison with a control group was possible either, making it very challenging to evaluate the actual intervention effect.

Regardless of the methodological difficulties, this study is one of the few to evaluate an intervention aimed at vocational students. In addition, the large number of participants contributes to the power of the study and allowed for a thorough analysis of not only dietary and physical activity behaviour, but also its determinants.

\section{Conclusions}

The aim of this study was to investigate the effect of the school-based, peer-delivered intervention Healthy by Design on the (determinants of) dietary and physical activity behaviour of vocational students and in addition investigate the effect of the intervention dose received on these outcomes. The behavioural intervention effects over time were restricted to an increase of moderate physical activity and an increase in the physical activity guideline knowledge under 18 . The received intervention dose was found to influence both (the determinants of) dietary and physical activity behaviour. A low intervention dose showed a negative effect on some behavioural determinants. A high intervention dose however showed a strong association with more healthy dietary and physical activity behaviour. This suggests that receiving a high dose of this intervention leads to more healthy dietary and physical activity behaviour in vocational students.

Author Contributions: Conceptualization, G.K. and S.d.V.; methodology, G.K. and S.d.V.; formal analysis, G.K., A.K. and T.G.; investigation, G.K. and A.K.; data curation, G.K.; writing-original draft preparation, A.K. and T.G.; writing - review and editing, G.K. and S.d.V.; supervision, G.K. and S.d.V.; project administration, G.K.; funding acquisition, G.K. and S.d.V.. All authors have read and agreed to the published version of the manuscript.

Funding: This research was funded by The Netherlands Organisation for Health Research and Development (ZonMw project number 531001111).

Institutional Review Board Statement: The study was not within the scope of the Dutch Medical Research Involving Human Subjects Act and therefore exempted from review by the Medical Ethics Committee Southwest Holland [METC nr 17-088].

Informed Consent Statement: A digital informed consent was obtained from all subjects involved in the study.

Data Availability Statement: The data presented in this study are available on request from the corresponding author. The data are not publicly available due to to the original consent not containing approval for public data sharing.

Acknowledgments: In this section, you can acknowledge any support given which is not covered by the author contribution or funding sections. This may include administrative and technical support, or donations in kind (e.g., materials used for experiments). 
Conflicts of Interest: The authors declare no conflict of interest. The funders had no role in the design of the study; in the collection, analyses, or interpretation of data; in the writing of the manuscript, or in the decision to publish the results.

\section{Appendix A}

Table A1. Mean scores for dietary and physical activity behaviours

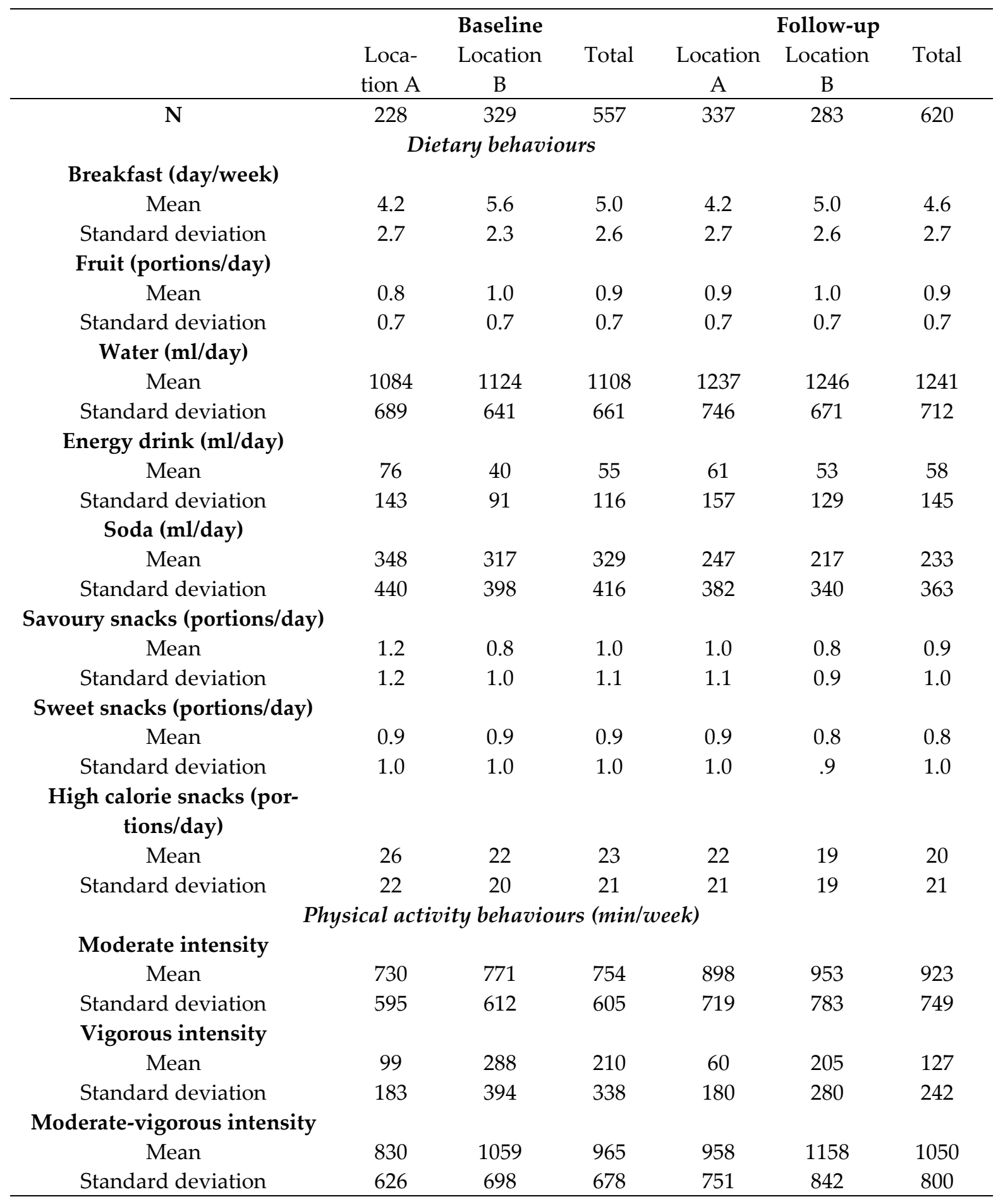

\section{References}

1. Wyatt, S.B.; Winters, K.P.; Dubbert, P.M. Overweight and obesity: prevalence, consequences, and causes of a growing public health problem. Am J Med Sci 2006, 331, 166-174, doi:10.1097/00000441-200604000-00002. 
2. Kumanyika, S.K.; Obarzanek, E.; Stettler, N.; Bell, R.; Field, A.E.; Fortmann, S.P.; Franklin, B.A.; Gillman, M.W.; Lewis, C.E.; Poston, W.C., 2nd, et al. Population-based prevention of obesity: the need for comprehensive promotion of healthful eating, physical activity, and energy balance: a scientific statement from American Heart Association Council on Epidemiology and Prevention, Interdisciplinary Committee for Prevention (formerly the expert panel on population and prevention science). Circulation 2008, 118, 428-464, doi:10.1161/circulationaha.108.189702.

3. Aune, D.; Giovannucci, E.; Boffetta, P.; Fadnes, L.T.; Keum, N.; Norat, T.; Greenwood, D.C.; Riboli, E.; Vatten, L.J.; Tonstad, S. Fruit and vegetable intake and the risk of cardiovascular disease, total cancer and all-cause mortality-a systematic review and dose-response meta-analysis of prospective studies. International journal of epidemiology 2017, 46, 1029-1056, doi:10.1093/ije/dyw319.

4. Bellou, V.; Belbasis, L.; Tzoulaki, I.; Evangelou, E. Risk factors for type 2 diabetes mellitus: An exposure-wide umbrella review of meta-analyses. PloS one 2018, 13, e0194127-e0194127, doi:10.1371/journal.pone.0194127.

5. Lee, I.-M.; Shiroma, E.J.; Lobelo, F.; Puska, P.; Blair, S.N.; Katzmarzyk, P.T.; Group, L.P.A.S.W. Effect of physical inactivity on major non-communicable diseases worldwide: an analysis of burden of disease and life expectancy. The lancet 2012, 380, 219-229.

6. Wahid, A.; Manek, N.; Nichols, M.; Kelly, P.; Foster, C.; Webster, P.; Kaur, A.; Friedemann Smith, C.; Wilkins, E.; Rayner, M., et al. Quantifying the Association Between Physical Activity and Cardiovascular Disease and Diabetes: A Systematic Review and Meta-Analysis. Journal of the American Heart Association 2016, 5, e002495, doi:10.1161/JAHA.115.002495.

7. Must, A. Does overweight in childhood have an impact on adult health? Nutr Rev 2003, 61, 139-142, doi:10.1301/nr.2003.apr.139-142.

8. Maffeis, C.; Tato, L. Long-term effects of childhood obesity on morbidity and mortality. Horm Res 2001, 55 Suppl 1, 42-45, doi:10.1159/000063462.

9. McVeigh, J.A.; Winkler, E.A.H.; Howie, E.K.; Tremblay, M.S.; Smith, A.; Abbott, R.A.; Eastwood, P.R.; Healy, G.N.; Straker, L.M. Objectively measured patterns of sedentary time and physical activity in young adults of the Raine study cohort. International Journal of Behavioral Nutrition and Physical Activity 2016, 13, 41, doi:10.1186/s12966-016-0363-0.

10. Pearson, N.; Atkin, A.J.; Biddle, S.J.; Gorely, T.; Edwardson, C. Patterns of adolescent physical activity and dietary behaviours. Int J Behav Nutr Phys Act 2009, 6, 45, doi:10.1186/1479-5868-6-45.

11. Piirtola, M.; Kaprio, J.; Kujala, U.M.; Heikkilä, K.; Koskenvuo, M.; Svedberg, P.; Silventoinen, K.; Ropponen, A. Association between education and future leisure-time physical inactivity: a study of Finnish twins over a 35-year follow-up. BMC public health 2016, 16, 720, doi:10.1186/s12889-016-3410-5.

12. Dirven, H.-J.; van der Mooren, F. Drinken, roken, bewegen en overgewicht en de onderwijsloopbaan [Drinking, smoking, physical activity and overweight in the educational trajectory]. Availabe online: https://www.cbs.nl/nl-nl/achtergrond/2012/20/drinken-roken-bewegen-en-overgewicht-en-de-onderwijsloopbaan (accessed on 14 April 2020).

13. Bonevski, B.; Guillaumier, A.; Paul, C.; Walsh, R. The vocational education setting for health promotion: a survey of students' health risk behaviours and preferences for help. Health Promotion Journal of Australia 2013, 24, 185-191, doi:10.1071/HE13047.

14. Rijpstra, A.; Bernaards, C. De leefstijl van MBO studenten in Nederland 2009/2010 [Lifestyle of vocational students in The Netherlands 2009/2010]; TNO: Leiden, 2011.

15. Sawyer, S.M.; Afifi, R.A.; Bearinger, L.H.; Blakemore, S.-J.; Dick, B.; Ezeh, A.C.; Patton, G.C. Adolescence: a foundation for future health. The Lancet 2012, 379, 1630-1640.

16. Nelson, M.C.; Story, M.; Larson, N.I.; Neumark-Sztainer, D.; Lytle, L.A. Emerging Adulthood and College-aged Youth: An Overlooked Age for Weight-related Behavior Change. Obesity 2008, 16, 2205-2211, doi:10.1038/oby.2008.365. 
17. Paulussen, T.; Buijs, G.; Zoonen van, R.; Akker van den, E.; Keulen van, H.; Empelen van, P. Voorstudie effect-onderzoek naar Gezonde School in Nederland. ; TNO: Leiden, 2016.

18. Heijden von, A.; Collard, D. Inventarisatie van leefstijlinterventies binnen de mbo-setting [Inventory of lifestyle interventions in secondary vocational education]; Mulier Institute 's Hertogenbosch, The Netherlands, 2011.

19. De Bourdeaudhuij, I.; Van Cauwenberghe, E.; Spittaels, H.; Oppert, J.M.; Rostami, C.; Brug, J.; Van Lenthe, F.; Lobstein, T.; Maes, L. School-based interventions promoting both physical activity and healthy eating in Europe: a systematic review within the HOPE project. Obes Rev 2011, 12, 205-216, doi:10.1111/j.1467-789X.2009.00711.x.

20. Gonzalez-Suarez, C.; Worley, A.; Grimmer-Somers, K.; Dones, V. School-based interventions on childhood obesity: a meta-analysis. Am J Prev Med 2009, 37, 418-427, doi:10.1016/j.amepre.2009.07.012.

21. Kriemler, S.; Meyer, U.; Martin, E.; van Sluijs, E.M.; Andersen, L.B.; Martin, B.W. Effect of school-based interventions on physical activity and fitness in children and adolescents: a review of reviews and systematic update. Br J Sports Med 2011, 45, 923-930, doi:10.1136/bjsports-2011-090186.

Hulteen, R.M.; Waldhauser, K.J.; Beauchamp, M.R. Promoting Health-Enhancing Physical Activity: a State-of-the-art Review of Peer-Delivered Interventions. Curr Obes Rep 2019, 8, 341-353, doi:10.1007/s13679-019-00366-w.

Ginis, K.A.; Nigg, C.R.; Smith, A.L. Peer-delivered physical activity interventions: an overlooked opportunity for physical activity promotion. Transl Behav Med 2013, 3, 434-443, doi:10.1007/s13142-013-0215-2.

24. Yip, C.; Gates, M.; Gates, A.; Hanning, R.M. Peer-led nutrition education programs for school-aged youth: a systematic review of the literature. Health Educ Res 2016, 31, 82-97, doi:10.1093/her/cyv063.

25. Story, M.; Lytle, L.A.; Birnbaum, A.S.; Perry, C.L. Peer-Led, School-Based Nutrition Education for Young Adolescents: Feasibility and Process Evaluation of the TEENS Study. Journal of School Health 2002, 72, 121-127, doi:10.1111/j.1746-1561.2002.tb06529.x.

26. Aceves-Martins, M.; Llaurado, E.; Tarro, L.; Morina, D.; Papell-Garcia, I.; Prades-Tena, J.; Kettner-Hoeberg, H.; Puiggros, F.; Arola, L.; Davies, A., et al. A School-Based, Peer-Led, Social Marketing Intervention To Engage Spanish Adolescents in a Healthy Lifestyle ("We Are Cool"-Som la Pera Study): A Parallel-Cluster Randomized Controlled Study. Child Obes 2017, 13, 300-313, doi:10.1089/chi.2016.0216.

27. Bartholomew, L.K.; Parcel, G.S.; Kok, G.; Gottlieb, N.H.; Fernandez, M.E. Planning health promotion programs: An intervention mapping approach (3rd ed.); Jossey-Bass: San Francisco, CA, 2011.

28. Kremers, S.P.; Visscher, T.L.; Seidell, J.C.; van Mechelen, W.; Brug, J. Cognitive determinants of energy balance-related behaviours: measurement issues. Sports Med 2005, 35, 923-933, doi:10.2165/00007256-200535110-00001.

29. Kremers, S.P.; De Bruijn, G.-J.; Visscher, T.L.; Van Mechelen, W.; De Vries, N.K.; Brug, J. Environmental influences on energy balance-related behaviors: a dual-process view. International Journal of Behavioral Nutrition and Physical Activity 2006, $3,9$.

30. Kloek, G.; Pries, F.; Doorn van, F.; Vries de, S. Healthy by Design: using participatory design methods to develop a healthy lifestyle intervention for vocational students. In Proceedings of Design4Health, Amsterdam.

31. Ajzen, I. The theory of planned behavior. Organizational Behavior and Human Decision Processes 1991, 50, 179 - 211, doi:https://doi.org/10.1016/0749-5978(91)90020-T.

32. Armitage, C.J.; Conner, M. Efficacy of the theory of planned behaviour: A meta-analytic review. British Journal of Social Psychology 2001, 10.1348/014466601164939, doi:10.1348/014466601164939.

33. Draper, C.E.; Grobler, L.; Micklesfield, L.K.; Norris, S.A. Impact of social norms and social support on diet, physical activity and sedentary behaviour of adolescents: a scoping review. Child Care Health Dev 2015, 41, 654-667, doi:10.1111/cch.12241.

34. Stok, F.M.; de Vet, E.; de Ridder, D.T.; de Wit, J.B. The potential of peer social norms to shape food intake in adolescents and young adults: a systematic review of effects and moderators. Health Psychol Rev 2016, 10, 326-340, doi:10.1080/17437199.2016.1155161. 
35. Giles, E.L.; Brennan, M. Changing the lifestyles of young adults. Journal of Social Marketing 2015, 5, $206-225$.

36. Ryan, R.M.; Deci, E.L. Self-determination theory and the facilitation of intrinsic motivation, social development, and well-being. American Psychologist 2000, 55, 68-78, doi:10.1037/0003-066X.55.1.68.

37. Ng, J.Y.Y.; Ntoumanis, N.; Thøgersen-Ntoumani, C.; Deci, E.L.; Ryan, R.M.; Duda, J.L.; Williams, G.C. Self-Determination Theory Applied to Health Contexts. Perspectives on Psychological Science 2012, 7, 325-340, doi:10.1177/1745691612447309.

38. Ryan, R.M.; Patrick, H.; Deci, E.L.; Williams, G.C. Facilitating health behaviour change and its maintenance: Interventions based on self-determination theory. The European Health Psychologist 2008, 10, 2-5.

39. Vaquero-Solis, M.; Gallego, D.I.; Tapia-Serrano, M.A.; Pulido, J.J.; Sanchez-Miguel, P.A. School-based Physical Activity Interventions in Children and Adolescents: A Systematic Review. Int J Environ Res Public Health 2020, 17, doi:10.3390/ijerph17030999.

40. Teixeira, P.J.; Carraça, E.V.; Markland, D.; Silva, M.N.; Ryan, R.M. Exercise, physical activity, and self-determination theory: A systematic review. International Journal of Behavioral Nutrition and Physical Activity 2012, 9, 78, doi:10.1186/1479-5868-9-78.

41. Minary, L.; Trompette, J.; Kivits, J.; Cambon, L.; Tarquinio, C.; Alla, F. Which design to evaluate complex interventions? Toward a methodological framework through a systematic review. BMC Med Res Methodol 2019, 19, 92, doi:10.1186/s12874-019-0736-6.

42. Van Sluijs, E.M.; Kriemler, S. Reflections on physical activity intervention research in young people-dos, don'ts, and critical thoughts. International journal of behavioral nutrition and physical activity 2016, 13, 25.

43. Owen, K.B.; Smith, J.; Lubans, D.R.; Ng, J.Y.Y.; Lonsdale, C. Self-determined motivation and physical activity in children and adolescents: A systematic review and meta-analysis. Preventive Medicine 2014, 67, 270-279, doi:10.1016/j.ypmed.2014.07.033.

44. MBO Raad. Dutch VET. Availabe online: https://www.mboraad.nl/english (accessed on 14 April 2020).

45. Michie, S.; Richardson, M.; Johnston, M.; Abraham, C.; Francis, J.; Hardeman, W.; Eccles, M.P.; Cane, J.; Wood, C.E. The behavior change technique taxonomy (v1) of 93 hierarchically clustered techniques: building an international consensus for the reporting of behavior change interventions. Annals of behavioral medicine 2013, 46, 81-95.

46. wetten.nl - Regeling - Wet medisch-wetenschappelijk onderzoek met mensen - BWBR0009408. Availabe online: https://wetten.overheid.nl/BWBR0009408/2020-01-01 (accessed on

47. De Gezondheidsmonitors I Gezondheidsmonitor. Availabe online: https://www.monitorgezondheid.nl/ (accessed on

48. Wendel-Vos, G.C.W.; Schuit, A.J.; Saris, W.H.M.; Kromhout, D. Reproducibility and relative validity of the short questionnaire to assess health-enhancing physical activity. Journal of clinical epidemiology 2003, 56, 1163-1169.

49. Levesque, C.S.; Williams, G.C.; Elliot, D.; Pickering, M.A.; Bodenhamer, B.; Finley, P.J. Validating the theoretical structure of the Treatment Self-Regulation Questionnaire (TSRQ) across three different health behaviors. Health Education Research 2006, 22, 691-702, doi:10.1093/her/cyl148.

50. Kromhout, D.; Spaaij, C.; de Goede, J.; Weggemans, R. The 2015 Dutch food-based dietary guidelines. European journal of clinical nutrition 2016, 70, 869-878.

51. Weggemans, R.M.; Backx, F.J.; Borghouts, L.; Chinapaw, M.; Hopman, M.T.; Koster, A.; Kremers, S.; van Loon, L.J.; May, A.; Mosterd, A. The 2017 Dutch physical activity guidelines. International Journal of Behavioral Nutrition and Physical Activity 2018, 15, 58 .

52. Ball, K.; Jeffery, R.W.; Abbott, G.; McNaughton, S.A.; Crawford, D. Is healthy behavior contagious: associations of social norms with physical activity and healthy eating. Int J Behav Nutr Phys Act 2010, 7, 86, doi:10.1186/1479-5868-7-86.

53. Pirie, P.L.; Stone, E.J.; Assaf, A.R.; Flora, J.A.; Maschewsky-Schneider, U. Program evaluation strategies for community-based health promotion programs: perspectives from the cardiovascular disease community research and demonstration studies. Health Educ Res 1994, 9, 23-36, doi:10.1093/her/9.1.23. 
54. von Bothmer, M.I.K.; Fridlund, B. Gender differences in health habits and in motivation for a healthy lifestyle among Swedish university students. Nursing and Health Sciences 2005, 10.1111/j.1442-2018.2005.00227.x, doi:10.1111/j.1442-2018.2005.00227.x.

55. Mozaffarian, D.; Hao, T.; Rimm, E.B.; Willett, W.C.; Hu, F.B. Changes in diet and lifestyle and long-term weight gain in women and men. New England Journal of Medicine 2011, 10.1056/NEJMoa1014296, doi:10.1056/NEJMoa1014296.

56. Hjartåker, A.; Lund, E. Relationship between dietary habits, age, lifestyle, and socio-economic status among adult Norwegian women. The Norwegian Women and Cancer Study. European Journal of Clinical Nutrition 1998, 52, 565-572, doi:10.1038/sj.ejen.1600608.

57. Phillips, L.A.; Johnson, M.A. Interdependent Effects of Autonomous and Controlled Regulation on Exercise Behavior. Personality and Social Psychology Bulletin 2018, 10.1177/0146167217733068, doi:10.1177/0146167217733068.

58. de Barros, M.V.G.; Nahas, M.V.; Hallal, P.C.; de Farias Júnior, J.C.; Florindo, A.A.; de Barros, S.S.H. Effectiveness of a School-Based Intervention on Physical Activity for High School Students in Brazil: The Saude na Boa Project. 2009, 6, 163, doi:10.1123/jpah.6.2.163.

59. Trude, A.C.B.; Kharmats, A.Y.; Jones-Smith, J.C.; Gittelsohn, J. Exposure to a multi-level multi-component childhood obesity prevention community-randomized controlled trial: patterns, determinants, and implications. Trials 2018, 19, 287, doi:10.1186/s13063-018-2663-y.

60. Paeratakul, S.; Popkin, B.; Kohlmeier, L.; Hertz-Picciotto, I.; Guo, X.; Edwards, L. Measurement error in dietary data: Implications for the epidemiologic study of the diet-disease relationship. European Journal of Clinical Nutrition 1998, 52, 722-727, doi:10.1038/sj.ejcn.1600633.

61. Nicolaou, M.; Gademan, M.G.J.; Snijder, M.B.; Engelbert, R.H.H.; Dijkshoorn, H.; Terwee, C.B.; Stronks, K. Validation of the SQUASH Physical Activity Questionnaire in a Multi-Ethnic Population: The HELIUS Study. PloS one 2016, 11, e0161066, doi:10.1371/journal.pone.0161066. 